\title{
Effect of silica content on mechanical and microstructure behaviour of resistance spot welded advanced automotive TRIP steels
}

Paranthaman V ( $\sim$ paranthphd@gmail.com )

Adhi College of Engineering and Technology https://orcid.org/0000-0002-9205-7439

Shanmuga Sundaram K

Anna University Chennai

L Natrayan

Anna University Chennai

\section{Research Article}

Keywords: Resistance spot welding, TRIP steel, SiC, Shear tensile, Fracture surface, Microstructure, Mechanical properties

Posted Date: February 25th, 2021

DOI: https://doi.org/10.21203/rs.3.rs-163804/v1

License: (c) (i) This work is licensed under a Creative Commons Attribution 4.0 International License. Read Full License 


\section{Abstract}

This research investigates the effect of $\mathrm{SiC}$ wt\% on mechanical and microstructure behavior of transformation induced plasticity (TRIP) 780 steels by resistance spot welding. The resistance spot welded samples were characterized for their properties such as hardness, tensile shear, scanning electron microscope, X-ray diffraction, ductility ratio and elongation. Results showed that the width of the nugget was closely associated with shear failure of the spot welds. X-ray diffraction analysis illustrated that the weld steels chemical composition improved in the heat-affected zones and retained austenite detected due to the influence of Si and $\mathrm{C}$. Sample 4 microstructure exposed the equiaxed dimple and finer dendrites in the fusion zone. It also exhibited maximum force and fracture energy. Nano hardness was significantly decreased in the fusion zone of sample 4 due to the interface among micro alloying elements and the formation of nonmetallic presences that affected the TRIP steel hardness. Low ductility ratios were observed in steel 4 than the other weld steels due to higher tensile shear strength (TSS) and cross-tension strength (CTS) results. Fracture analysis exhibited ductile fracture with dimples and dendrites in the TRIP steels surface. The spot-welded samples mechanical properties are correlated to chemical elements, mainly Si existing in casted TRIP steels through the cooling phase of the resistance spot welding process.

\section{Introduction}

In recent years, automobile manufacturers are in demand to improve the vehicles fuel efficiency and safety standards [1]. It has essential to design and select material with high strength, formability, and good weldability [2]. A new challenge to weld the high strength steel research is continue growing [3]. The new generation of high-strength steel has the most potential development in quantitative research [4]. Transformation induced plasticity (TRIP) steel is a newly developed high-strength steel used for automotive application due to their excellent ductility, strong plastic product, and strain hardening index [5]. However, TRIP high-strength steel has a higher $\mathrm{C}, \mathrm{Mn}, \mathrm{Si}, \mathrm{Al}$, and other alloying elements with better weldability than other steels [6],[7]. In recent years, resistance spot welding is the primary welding method used to join the TRIP steels for automobile structure application[8]. Many researchers have studied the pulsed welding and heat treatment on TRIP steels after welding $[9,10]$. Park et al. studied the resistance spot welding joints of high strength TRIP590 steel. The results exposed that fracture mode, and nugget diameter affects the weld joints fracture characteristics[11]. Stadler $\mathrm{M}$ et al. carried out resistance spot welding on TRIP steel with bainitic ferrite by two pulses of current. Their results showed that tensile shear behavior has improved [12]. Emre et al. investigated the fracture mode of TRIP800 steel using the resistance spot welding method. The nugget diameter should be at least 4.5 thicknesses to meet the shear tension of the spot-welded joint [13]. Sajjadi Nikoo et al. examined the effect of three different types of post-weld heat treatment on the TRIP 700 steel resistance spot welds. The results showed that according to the applied pulse level, the welds mechanical properties were affected by mechanisms such as hardness reduction in the FZ due to the tempering of martensite. Silicon carbide ( $\mathrm{SiC})$ is the hard ceramic particles, it has mainly used as reinforcement to improve the material strength[14]. The welding 
cycle, holding time, and welding time were higher, and the pulse current level was very low [15]. Yu et al. obtained the optimum welding parameters for resistance spot welding of TRIP800 steel such as 10kA weld current, 15 cycles weld time, 10 cycles cool time, $12 \mathrm{sec}$ squeeze time and 4 to $10 \mathrm{kN}$ weld force [16]. Eftekhari et al. reported that the second pulse current was lower than the first pulse. The size of prior austenite grains has a significant effect on the mechanical properties [17]. Perez-Medina et al. reported that martensite content was $23 \%$ in the fusion zone and as high as $30 \%$ in the heat-affected area. Large amounts of brittle martensite were formed in the fusion zone and reduced the weld joints toughness [18].

Previous research works reveal the details of mechanical and microstructure properties of TRIP steel weld joints. TRIP 780 high strength steel has mainly used as bumper cross member material in the automobile application[18, 19]. Many authors reported on the resistance spot welding joint with reinforcement particles which were not finely dissolved in the nugget zone. Moreover, there are no research work reports on the mechanical properties of TRIP780 steel with varying SiC content In this research, resistance spot weld technique was used to study the effect of SiC content in casted TRIP 780 steel. The influence of hardness, X-ray diffraction, scanning electron microscope, tensile shear, ductility ratio, elongation, and fractography properties were investigated.

\section{Materials And Methods}

Different SiC content TRIP 780 sheets of steel were fabricated in the Kathiravan Metal Bellows India Private Limited - Chennai (TN, India). Silicon carbide with 1 to 3 weight percentages with 0.5 intervals was considered for this study shown in Table 1. Average particle size 10 micron were consider in this study [14]Steel alloys with SiC reinforcement were added to the crucible and were cast into $40 \times 40 \times 140 \mathrm{~mm}$ rectangle shape.

Table 1

Sample preparation

\begin{tabular}{|ll|}
\hline Sample No & SiC (wt\%) \\
\hline Steel -1 & 1.0 \\
\hline Steel - 2 & 1.5 \\
\hline Steel - 3 & 2.0 \\
\hline Steel - 4 & 2.5 \\
\hline Steel - 5 & 3.0 \\
\hline
\end{tabular}

For making weld specimens, casted ingots were heat-treated at $1200^{\circ} \mathrm{C}$ for 2 hours and then air chilled. After this heat treatment process, casted ingots were cut into $20 \mathrm{~mm} \times 20 \mathrm{~mm} \times 140 \mathrm{~mm}$ shape than heated at $1200^{\circ} \mathrm{C}$ for 45 mins and hot-rolled to a width of $5 \mathrm{~mm}$; the metals were cooled down to $400^{\circ} \mathrm{C}$ and were cold rolled to $2.5 \mathrm{~mm}$ width. Later, casted steel was cut in to longitudinal segments of $140 \mathrm{~mm}$ 
length, $40 \mathrm{~mm}$ breadth, and then mechanically rolled to an ending width of $1.5 \mathrm{~mm}$. Single-phase resistance spot weld machine showed in Fig. 1 (a). Resistance spot welding process parameters [21] such as weld current of $10 \mathrm{kA}$, weld time of 15 cycles, cool time of 10 cycles, squeeze time of $12 \mathrm{sec}$ and weld force of $4 \mathrm{kN}$ for each material were considered.

According to this standard, a copper electrode was considered for welding operations. Concerning the thickness of the sheets, an electrode with a $6 \mathrm{~mm}$ diameter was used. AWS D 8.9 standard was used to prepare the cast TRIP780 steel sheets for testing [22]. Figure 1 (b) showed the dimension of prepared specimens for testing. Scanning electron microscopy and optical microscopy were used to explore the weld sample cross-sections. The casted samples were polished using 1200 grit sand-paper with $0.3 \mu \mathrm{m}$ alumina suspension and etched with $2 \%$ Nital reagent before the measurements.

Table 2

Chemical composition wt\% of casted TRIP 780 steels

\begin{tabular}{|llllllllll|}
\hline S. No & Si & C & Mn & P & S & Al & Cu & Ti $+\mathbf{N b}$ & $\mathbf{C r}$ \\
\hline Steel - 1 & 1.46 & 0.23 & 2.25 & 0.065 & 0.0051 & 0.065 & 0.38 & 0.22 & 1.35 \\
Steel - 2 & 1.98 & 0.26 & 2.43 & 0.059 & 0.0056 & 0.094 & 0.32 & 0.26 & 1.67 \\
Steel - 3 & 2.25 & 0.25 & 2.54 & 0.053 & 0.0065 & 0.153 & 0.26 & 0.29 & 2.01 \\
\hline Steel - 4 & 2.54 & 0.31 & 2.72 & 0.045 & 0.0074 & 0.256 & 0.20 & 0.33 & 0.71 \\
\hline Steel - 5 & 2.98 & 0.27 & 2.16 & 0.041 & 0.0071 & 0.224 & 0.19 & 0.31 & 1.15 \\
\hline
\end{tabular}

The fractured specimens of the tensile shear and cross tensile tests were investigated to determine fracture types. TRIP 780 steel's mechanical behavior was studied using the tensile shear and cross tensile test as per AWS D8.9 standards [22]. Each test was repeated five times and the mean value with error plot was reported. Microhardness profile of welded samples was measured across the weld using a Vickers hardness tester at a load of $0.25 \mathrm{Kgf}$ for the duration of $15 \mathrm{~s}$. A computer-controlled universal testing machine at the cross-head speed of $0.5 \mathrm{~mm} / \mathrm{min}$ was used for the tensile shear measurement [23]. Table 2 showed the percentage of the chemical element of casted TRIP 780 steel alloys taken by atomic emission spectroscopy.

\section{Results And Discussion}

\subsection{Microstructural Evaluation}

Fig 2 exposes the SEM image of all five cast TRIP 780 sheets of steel consisting of multiphase of bainite $(B)$, ferrite $(F)$, retained austenite $(R A)$ and martensite $(M)[24]$. Fig 2 (a) shows the region of weld pulse includes the initial weld. This microstructure has martensite and some bainite in some areas. Fig 2 (b) shows the tempered structure along with the remained ferrite in this area. The grains are homogeneous in 
steel 3 (S3). It was difficult to isolate the annealed region because grains can be detected stretching and more refined with tempered martensite packs with a different orientation as observed in fig 2 (c).

In steel 4 (Fig. 2d), wide coarser polygonal aniline structures were formed in the weld nugget. Martensite was formed adjacent to each other with different orientations after the annealed grains toward the weld center. Figure 2 (d) and 2 (e) exposed that the martensite is getting fine at the adjacent welding. A substantial amount of bainite, martensite, retained austenite, and mostly ferrite is present in less than $1 \%$ of $\mathrm{Mn}$ as microstructures. A lower \% of $\mathrm{Mn}$ is often relevant to the austenite variability and increases the cooling period's ferritic reactions.

\subsection{Phase Evolution of cast TRIP steels}

Fig 3 shows the XRD patterns for heat-affected zone, base metal, and fusion zone of welded samples. The XRD patterns indicate that the presence of delta ferrite, austenite, martensite, and retained austenite phases due to the reaction of SiC reinforcement in TRIP steel. Peak intensity was found to vary with $\mathrm{Si}$ composition. It is observed that the peak shift was observed with increasing Si wt\%.

Fig 3 (a) shows the high peaks denoted ferrite and austenite in the base metal; these are the steel's essential elements. Base metal peaks reveal that the amount of retained austenite increases with increasing the Si reinforcement in each steel. Heat affected zone XRD peaks (fig $3 \mathrm{~b}$ ) reported retained austenite existence in each steels weld joints [25]. Fig 3 (c) shows the amount of retained austenite decreased in the fusion zones. It is evident from the XRD pattern that the diffraction intensity and broadening of the peaks vary with the volume fraction of Si reinforcement.

\subsection{Hardness}

The hardness profiles of weld regions are shown in Fig. 4. The fusion zone exhibited high hardness values then the base meal. All five Cast TRIP steels showed fusion zone hardness above $450 \mathrm{HV}$; In this case, steel 4 and steel 3 showed less hardness 460,485. While steel 1, steel 2, and steel 5 exhibited the maximum hardness of $545 \mathrm{HV}, 520 \mathrm{HV}$, and $615 \mathrm{HV}$, respectively. Steel 1, Steel 2, Steel 5 have lower carbon substances; however, $\mathrm{Cr} \%$ is higher with the comparison of steel 4 and steel 3 . Enhancement of $\mathrm{Cr}$ and interaction of Ti with $\mathrm{Mn}$ might cause an increase in the hardness of martensite.

The chemical composition of steel was influenced more in the fusion zone hardness during the resistance spot welding process and found retained austenite at a minimum level. Silica and carbon particulates was well-bonded in TRIP steels, it has constraint to increases the dislocation density and plastic deformation. The presence of high chemical components such as carbon, $\mathrm{Cr}$ and $\mathrm{Mn}$ content obtained increase hardness in the fusion zone. Steel 4 has the lowest hardness due to the interface among micro alloying elements and the formation of nonmetallic presences that affect the TRIP steel hardness.

Steel 5 has less carbon content than other considered steel. It has resisted the optimum energy absorption and deflection without affect the strength because the retained austenite percentage is low in 
the heat affected zone. Figure 5 shows the load curve in terms of the height of TRIP steels penetration depth. As shown in Fig. 5 the rate of indentation in constant load was respectively higher for Steel 4 and Steel 5 than other samples, which are due to transformed martensite to cementite and softening of ferrite tempered.

\subsection{Shear stretching and cross stretching}

The tensile shear strength (TSS), cross-tension strength (CTS), and elastic modulus results are shown in Table 3. Cross-tension strength test results were showed not many differences. Steel 1, Steel 2, Steel 3 exhibits the CTS value of $2.14 \pm 0.25 \mathrm{KN}, 2.21 \pm 0.36 \mathrm{KN}$ and $2.26 \pm 0.29 \mathrm{KN}$, respectively. The highest cross-tension strength value of $3.05 \pm 0.33$ was observed from sample 5 . Elastic modulus of steel 1 (209 $\pm 2 \mathrm{GPa})$, steel $2(205 \pm 3 \mathrm{GPa})$, steel $3(216 \pm 4 \mathrm{GPa})$, steel $4(200 \pm 2 \mathrm{GPa})$ and steel $5(225 \pm 3 \mathrm{GPa})$ were observed. Sample 5 exhibits the highest elastic modulus than all other steels in this study. A high elastic modulus demands a higher force to achieve a certain deformation. The ratio of cross-tension strength (CTS) and tensile shear strength (TSS) is called ductility ratio. Steel 5 and steel 3 have the highest ductility ratio as $0.165,0.149$ respectively.

Table 3

Results of ductility ratio and Elastic Modulus.

\begin{tabular}{|lllll|}
\hline Samples & $\begin{array}{l}\text { Cross-tension strength } \\
\text { Max. load (KN) }\end{array}$ & $\begin{array}{l}\text { Tensile shear strength } \\
\text { Max. load (KN) }\end{array}$ & $\begin{array}{l}\text { Ductility ratio } \\
\text { (CTS/ TSS) }\end{array}$ & $\begin{array}{l}\text { Elastic } \\
\text { Modulus, } \\
\text { GPa }\end{array}$ \\
\hline Steel 1 & $2.14 \pm 0.25$ & $15.2 \pm 0.25$ & 0.141 & $209 \pm 2$ \\
\hline Steel 2 & $2.21 \pm 0.36$ & $15.9 \pm 0.36$ & 0.139 & $205 \pm 3$ \\
\hline Steel 3 & $2.26 \pm 0.29$ & $17.6 \pm 0.29$ & 0.149 & $216 \pm 4$ \\
\hline Steel 4 & $2.23 \pm 0.25$ & $17.3 \pm 0.25$ & 0.135 & $200 \pm 2$ \\
\hline Steel 5 & $3.05 \pm 0.33$ & $18.5 \pm 0.33$ & 0.165 & $225 \pm 3$ \\
\hline
\end{tabular}

Maximum force and ductility ratio are shown in Fig. 6. Steel 5 exposed maximum tensile shear strength load peak with an average of $18.5 \pm 0.33 \mathrm{KN}$ and ductility ratio (CTS/TSS) of $0.165 \pm 0.004$. Steel 1 exhibits the lowest value of tensile shear strength, cross-tension strength, values of $15.2 \pm 0.25 \mathrm{KN}, 2.14 \pm$ $0.25 \mathrm{KN}$ respectively. Low ductility ratios were observed in steel 4 due to higher CTS results than all other weld steels.

Figure 7 shows the displacement in cross-tension weld samples. Maximum displacement and energy absorbed were high in steel 4 (6.86) due to the excellent relationship among these properties. Low displacement percentage observed in steel 1 (3.34), steel 2 (3.98), steel 3 (4.45), and steel 5 (4.42). The amount of both displacement and energy absorption has improved by $51 \%$. This improvement along with the observed microstructure for steel 4 (Fig. 2 d) showed the best situation for the fracture type. The 
existence of less tightness, along with an almost equiaxed and finer structure, makes brittle martensite flexible and makes the state of the interface closer to the peripheral.

Figure 8 shows the weld nugget failure energy for tensile shear and cross-tension tensile test. Results exposed that steel 1 , steel 2 , steel 3 , and steel 5 were low energy absorbed due to hardness high in the heat-affected zone and fusion zone of all spot weld joints, which illustrates breakability. Displacement and energy absorbed by steel 4 were certainly high compared to the rest of weld steels. Carbon content was less in steel 4 and required sustaining high displacement and low load.

\subsection{Fracture surface analysis}

Figure 9 shows the fracture surfaces SEM image of weld steels. Figure 9 (a) shows the failure of steel 1 sample with a combination of interface and peripheral fracture with about $40 \%$ of the interface fracture in the weld nugget. The weld nugget in Fig. 9(b) fractured in pull-out and almost peripheral mode. Separation in the weld occurred from its edge at the weld boundary line. Some intergranular fracture and cleavage facets were observed in steel 2. In this type of tension, the crack traverse moves from the joint groove in the weld nugget environment. Fractures resulting from cross-tension of pulsed samples showed Pull out fracture type, which is due to the joining of grain boundaries in the HAZ region, adjacent to the weld nugget. It is determined that the hardness of the weld nugget and the lower HAZ region, increase the desire to pull out failure in cross-fracture. Figure 9 (c) shows the weld nuggets adjacent detachment in the annealed region, which includes equiaxed cavities, dimples that are fractured and ductility. In Fig. 9 (d), fracture adjacent to the weld includes dendritic solidification of grains, growth orientation and microvoids combination is clear observed.

Steel 4 observed $70 \%$ yield load and crack propagation does not begin from the joint. According to Fig. 9 (d), as soon as it reaches to the weld region, changes its path with regard to re-austenitic grains which converted from columnar mode to half equiaxed mode. Also due to temper in the welding region, its hardness decreases and the failure toughness improves. The failure in sheet thickness at the annealed region occurs in the form of intergranular with coarse grains, and at the weld center, pull-out detachment is observed. Failure modes for steel 4 with a lower hardness were almost a pull-out fracture. A thickness and pull out separation were obtained, which was accrued by repeating the test in HAZ fracture zone and ruptured area. Steel 5 observed $20 \%$ yield load and mostly transgranular fracture areas with predominantly cleavage surfaces in the exterior layers of the weld and microvoids combination in the center of the weld detected in Fig. 9 (e). Dimples and dendrites were observed in the fracture surfaces.

\section{Conclusions}

In this present study, TRIP 780 steel with different wt\% of SiC reinforcement were successfully welded by resistance spot weld process. Post weld steels microstructure and mechanical properties were characterized and drawn to the following are drawn. 
- The XRD patterns indicate that the presence of delta ferrite, austenite, martensite, and retained austenite phases are due to the reaction of Si reinforcement in TRIP steel. Retained austenite volume fraction increases with the increasing silicon content.

- High chemical components such as $\mathrm{C}, \mathrm{Cr}$, and $\mathrm{Mn}$ content were obtained to increase hardness in the fusion zone. However, the fusion zone of Steel 4, which has maximum chemical elements, shows less hardness due to the interface among micro alloying elements and the formation of nonmetallic presences that affect the TRIP steel hardness.

- The microstructure of all steels in the fusion zone contains martensite primarily due to the prosperous chemical compositions of steels. A substantial amount of bainite, retained austenite, and mostly ferrite is included in the heat-affected zone.

- Steel 4 has less carbon content than the other considered steels in this study. It has resisted the optimum energy absorption and deflection without affecting the strength because the retained austenite percentage is low in heat-affected zone.

- The chemical composition of steel influenced the fusion zone hardness during the resistance spot welding process and found retained austenite at a minimum level. Silica and carbon particulates was well-bonded in TRIP steels, it has constraint to increases the dislocation density and plastic deformation.

- The partial failure of tensile shear strength results showed the joining of annealed region boundaries adjacent to the weld for steel samples. However, the results showed that the highest cross tensile shear were related to the steel 5 . But steel 4 having more absorbed energy, displacement and low ductility. Failure for all weld samples in cross tensile shear was at the pull out mode.

- Fracture surface analysis showed dimple mode fraction with the separation of dendrites in the crack observed. Steel 4 exposed equiaxed and smaller grain size rate.

This study claims that TRIP 780 steel with $2.5 \mathrm{wt} \%$ SiC significantly enhanced the hardness, ductility ratio, cross tensile shear and tensile shear strength properties. It has suitable for bumper cross member application in automobile industry.

\section{Declarations}

\section{Funding statement:}

This work was supported by the "Innovation research and development fund, Kathiravan Metal Bellows India Private Limited - Chennai" grant number IR\&D/0146/CH-007/2020.

Conflict of Interest: The authors declare that they have no conflict of interest.

\section{Availability of data and material -}

The datasets analyzed during the current study are available from the corresponding author on reasonable request. 
Author contributions:

V. Paranthaman: Supervision, Investigation, Writing- Reviewing and Editing.

K. Shanmuga Sundaram: Software, Writing, Supervision, Editing.

Natrayan L : Conceptualization, Methodology, Software.

\section{Compliance with ethical standards -}

This article does not contain any studies with human participants or animals performed by any of the authors.

Consent to participate - Not applicable

Consent for Publication - Not applicable

\section{Acknowledgment}

The authors thank Kathiravan Metal Bellows India Private Limited for its financial assistance.

\section{References}

1. Sousa N, Almeida A, Coutinho-Rodrigues J, Natividade-Jesus E (2018) Dawn of autonomous vehicles: Review and challenges ahead. Proc Inst Civ Eng Munic Eng 171:3-14. https://doi.org/10.1680/jmuen.16.00063

2. Moayedi H, Darabi R, Ghabussi A et al (2020) Weld orientation effects on the formability of tailor welded thin steel sheets. Thin-Walled Struct 149:106669. https://doi.org/10.1016/j.tws.2020.106669

3. Amirthalingam M (2020) Recent Trends and Challenges in Welding of Automotive Steels. Indian Weld J 53:52-59. https://doi.org/https://doi.org/10.22486/iwj.v53i2.195582

4. El-Sherbiny A, El-Fawkhry MK, Shash AY, El-Hossany T (2020) Replacement of silicon by aluminum with the aid of vanadium for galvanized TRIP steel. J Mater Res Technol 9:3578-3589. https://doi.org/10.1016/j.jmrt.2020.01.096

5. Soleimani M, Kalhor A, Mirzadeh H (2020) Transformation-induced plasticity (TRIP) in advanced steels: A review. Mater Sci Eng A 795:. https://doi.org/10.1016/j.msea.2020.140023

6. Li ZC, Zhang XT, Mou YJ et al (2020) Design of an effective heat treatment involving intercritical hardening for high-strength-high elongation of $0.2 \mathrm{C}-1.5 \mathrm{Al}-(6-8.5) \mathrm{Mn}-\mathrm{Fe}$ TRIP steels: microstructural evolution and deformation behaviour. Mater Sci Technol (United Kingdom) 36:500510. https://doi.org/10.1080/02670836.2020.1711614

7. Tan X, He H, Lu W et al (2020) Effect of matrix structures on TRIP effect and mechanical properties of low-C low-Si Al-added hot-rolled TRIP steels. Mater Sci Eng A 771:. https://doi.org/10.1016/j.msea.2019.138629 
8. Jeon WS, Sharma A, Jung JP (2020) Liquid metal embrittlement of galvanized TRIP steels in resistance spot welding. Metals (Basel) 10:1-23. https://doi.org/10.3390/met10060787

9. Papadioti I, Bellas I, Tzini MIT et al (2020) TRIP steels: A multiscale computational simulation and experimental study of heat treatment and mechanical behavior. Materials (Basel) 13:1-40. https://doi.org/10.3390/ma13020458

10. ZHANG Y, FU C, YI R, JU J (2020) Optimization of double-pulse process in resistance spot welding of hot stamped steel sheet. ISIJ Int 60:1284-1290. https://doi.org/10.2355/isijinternational.ISIJINT2019-579

11. Park SS, Lee SM, Cho Y et al (2008) Evaluation of resistance spot weld interfacial fractures in tensileshear tests of TRIP 590 steels. J Korean Inst Met Mater 46:672-682.

https://doi.org/10.5781/kwjs.2008.26.6.081

12. Stadler M, Gruber M, Schnitzer R, Hofer C (2020) Microstructural characterization of a double pulse resistance spot welded $1200 \mathrm{MPa}$ TBF steel. Weld World 64:335-343.

https://doi.org/10.1007/s40194-019-00835-9

13. Emre HE, Kaçar R (2016) Development of weld lobe for resistance spot-welded TRIP800 steel and evaluation of fracture mode of its weldment. Int J Adv Manuf Technol 83:1737-1747. https://doi.org/10.1007/s00170-015-7605-1

14. Senthil Kumar M, Mangalaraja RV, Senthil Kumar R, Natrayan L (2019) Processing and characterization of AA2024/Al203/SiC reinforces hybrid composites using squeeze casting technique. Iran J Mater Sci Eng 16:55-67. https://doi.org/10.22068/ijmse.16.2.55

15. Sajjadi-Nikoo S, Pouranvari M, Abedi A, Ghaderi AA (2018) In situ postweld heat treatment of transformation induced plasticity steel resistance spot welds. Sci Technol Weld Join 23:71-78. https://doi.org/10.1080/13621718.2017.1323174

16. Yu Y, Wang F, Yang Z (2012) Study on resistance spot welding technology and properties of TRIP800 high strength steel sheet. Adv Mater Res 391-392:661-665. https://doi.org/10.4028/www.scientific.net/AMR.391-392.661

17. Eftekharimilani P, van der Aa EM, Hermans MJM, Richardson IM (2017) Microstructural characterisation of double pulse resistance spot welded advanced high strength steel. Sci Technol Weld Join 22:545-554. https://doi.org/10.1080/13621718.2016.1274848

18. Perez-Medina GY, López HF, Zambrano P, Reyes-Valdés FA (2013) Microstructural effects on the mechanical integrity of a TRIP-800 steel welded by laser-CO2 process. J Mater Eng Perform 22:607612. https://doi.org/10.1007/s11665-012-0282-4

19. Schmitt JH, lung $T$ (2018) New developments of advanced high-strength steels for automotive applications. Comptes Rendus Phys 19:641-656. https://doi.org/10.1016/j.crhy.2018.11.004

20. Baluch N, Udin ZM, Abdullah CS (2014) Advanced High Strength Steel in Auto Industry: an Overview. Eng Technol Appl Sci Res 4:686-689. https://doi.org/10.48084/etasr.444

21. Erencan A, Rukiye E (2019) Shunting effects on the resistance spot welding parameters of DP600. Mater Test 62:97-103. https://doi.org/https://doi.org/10.3139/120.111455 
22. Rajarajan C, Sivaraj P, Balasubramanian V (2020) Microstructural analysis of weld nugget properties on resistance spot-welded advance high strength dual phase $(a+a /)$ steel joints. Mater Res Express 7:. https://doi.org/10.1088/2053-1591/ab654d

23. Natrayan L, Senthil Kumar M (2020) An integrated artificial neural network and Taguchi approach to optimize the squeeze cast process parameters of AA6061/Al203/SiC/Gr hybrid composites prepared by novel encapsulation feeding technique. Mater Today Commun 25:101586. https://doi.org/10.1016/j.mtcomm.2020.101586

24. Kumar R, Dwivedi RK, Ahmed S (2020) Influence of Multiphase High Silicon Steel (Retained Austenite-RA, Ferrite- F, Bainite-B and Pearlite-P) and Carbon Content of RA-CY on Rolling/Sliding Wear. Silicon. https://doi.org/10.1007/s12633-020-00682-0

25. Wang T, Zhang M, Liu R, dong et al (2020) Effect of welding speed on microstructure and mechanical properties of laser-welded transformation induced plasticity (TRIP) steels. J Iron Steel Res Int 27:1087-1098. https://doi.org/10.1007/s42243-020-00397-x

\section{Figures}




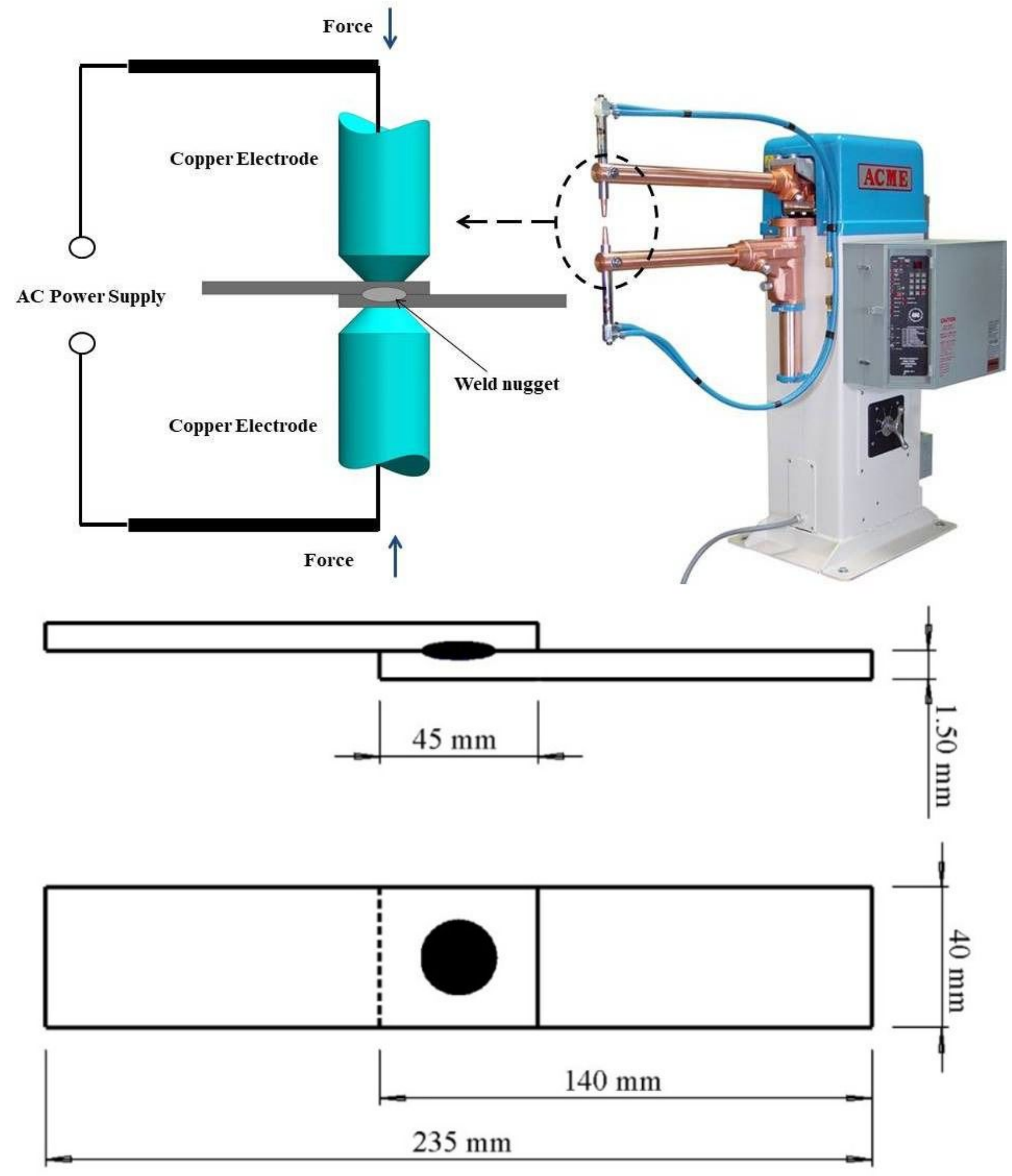

Figure 1

Top (a) Single-phase resistance spot weld machine. Bottom (b) AWS D8.9 standard TRIP 780 steel 


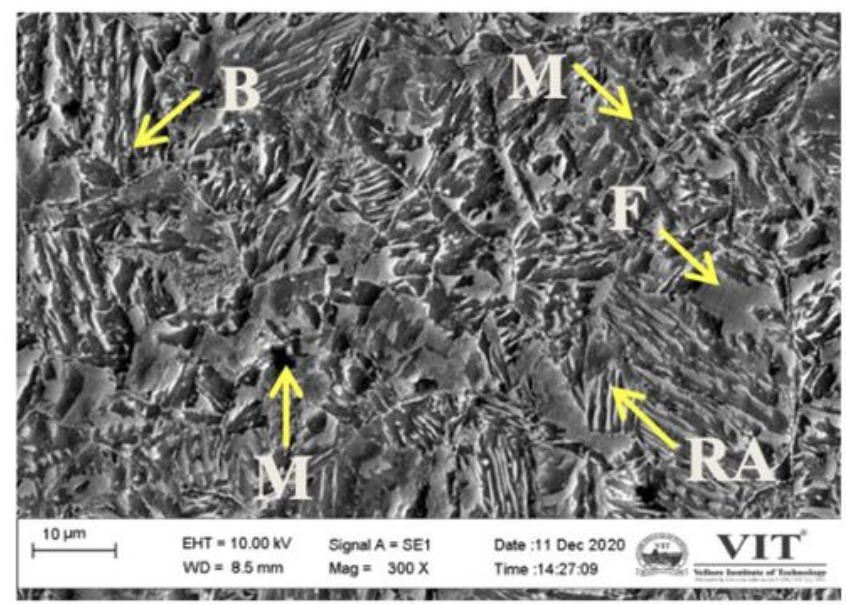

a) Steel 1

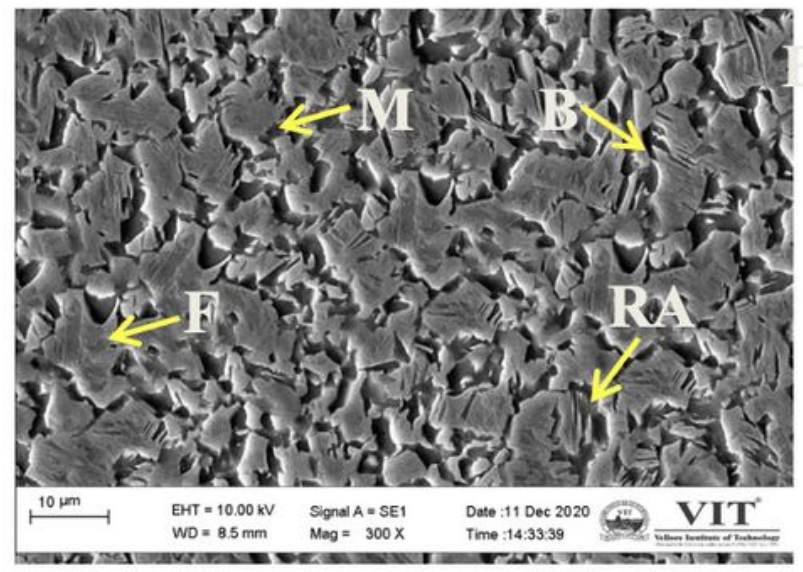

c) Steel 3

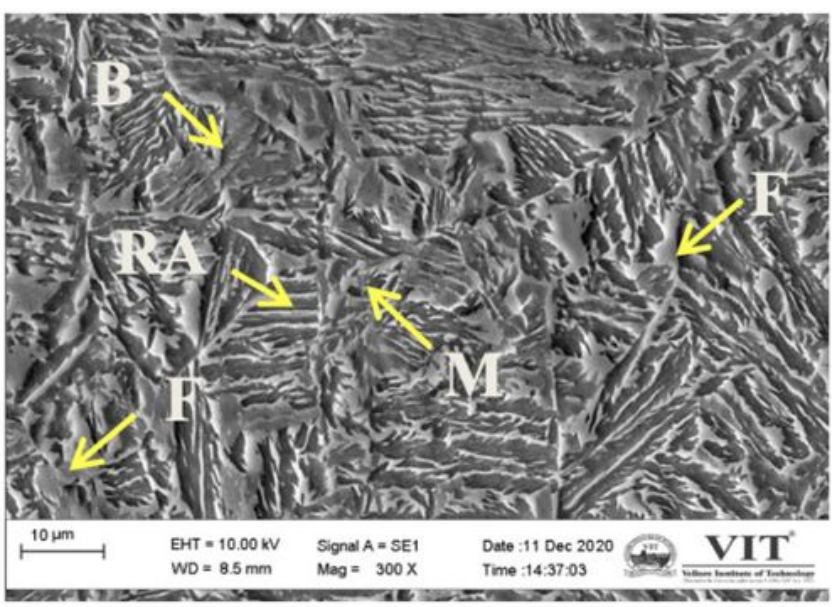

b) Steel 2

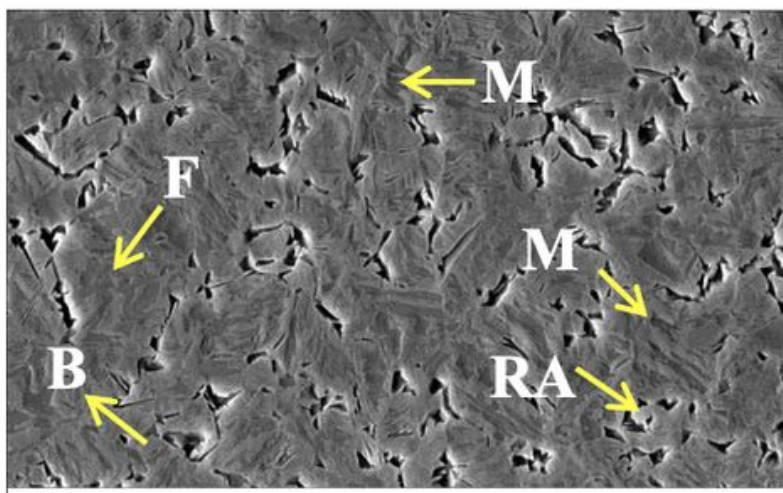

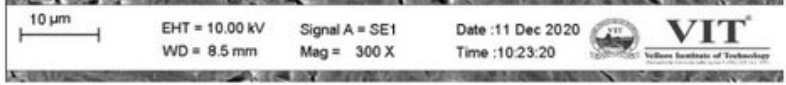

d) Steel 4

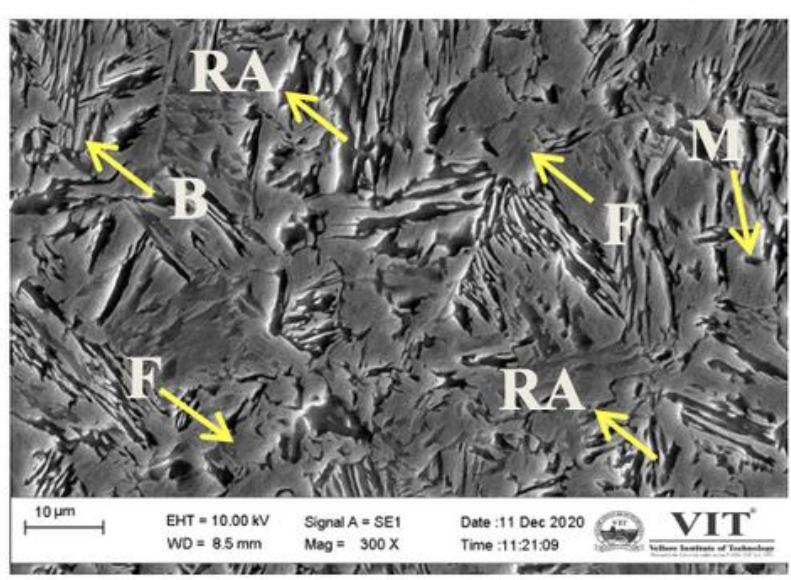

e) Steel 5
M-Martensite

B- Bainite

F- Ferrite

RA - Retained austenite

Figure 2

Microstructure of welding adjacent annealed region 


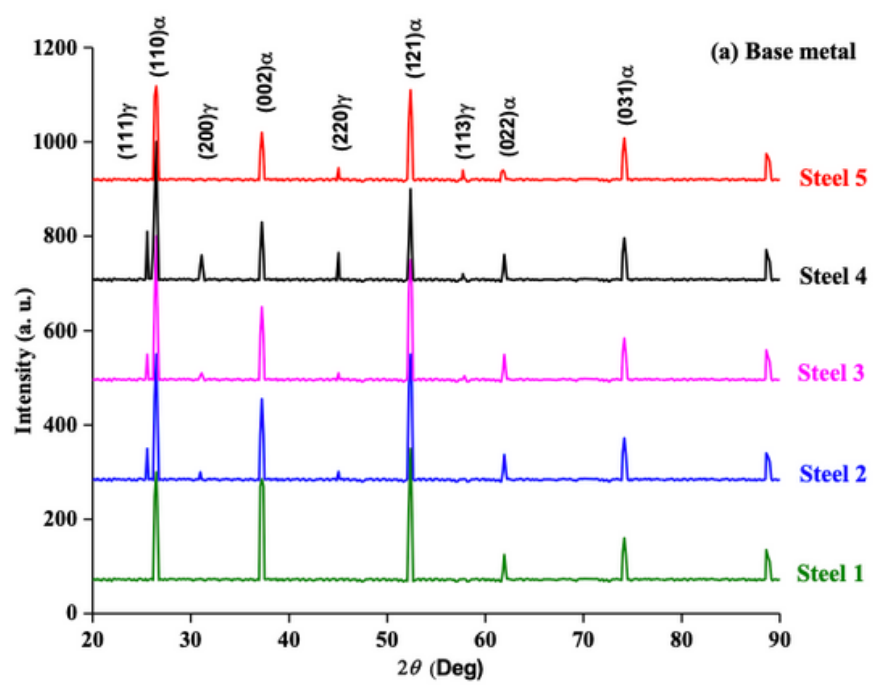

Fig 3(a) Base metal XRD pattern

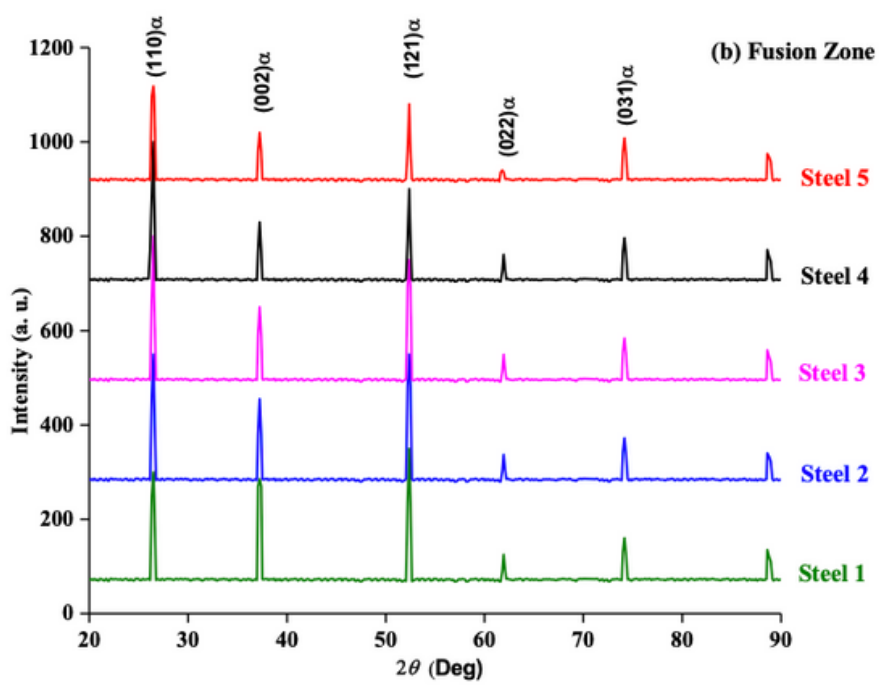

Fig 3(b) Fusion zone XRD pattern

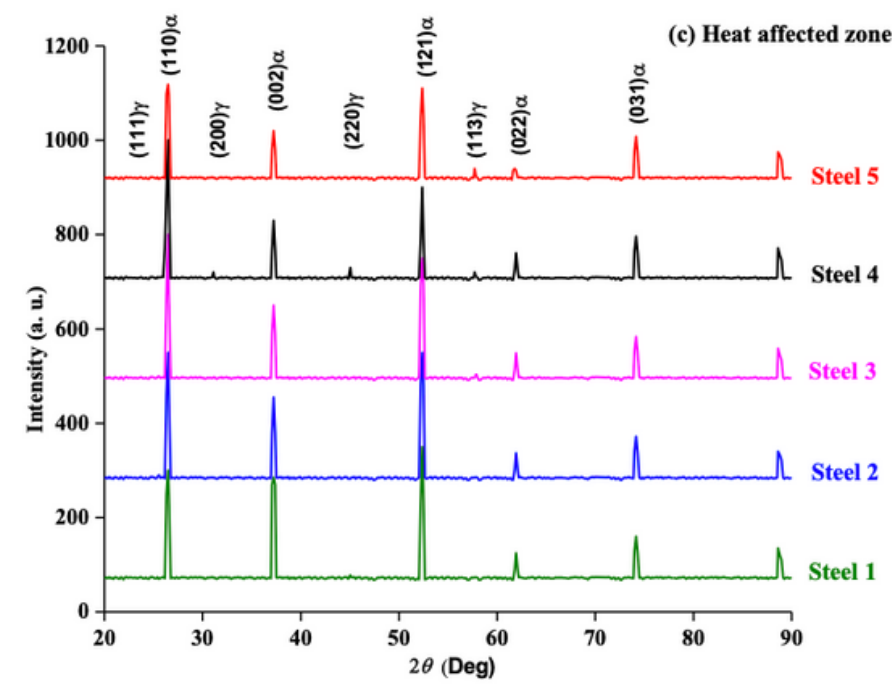

Fig 3(c) Heat affected zone XRD pattern

\section{Figure 3}

XRD pattern for $\mathrm{BM}, \mathrm{FZ}$ and $\mathrm{HAZ}$ for all steels 


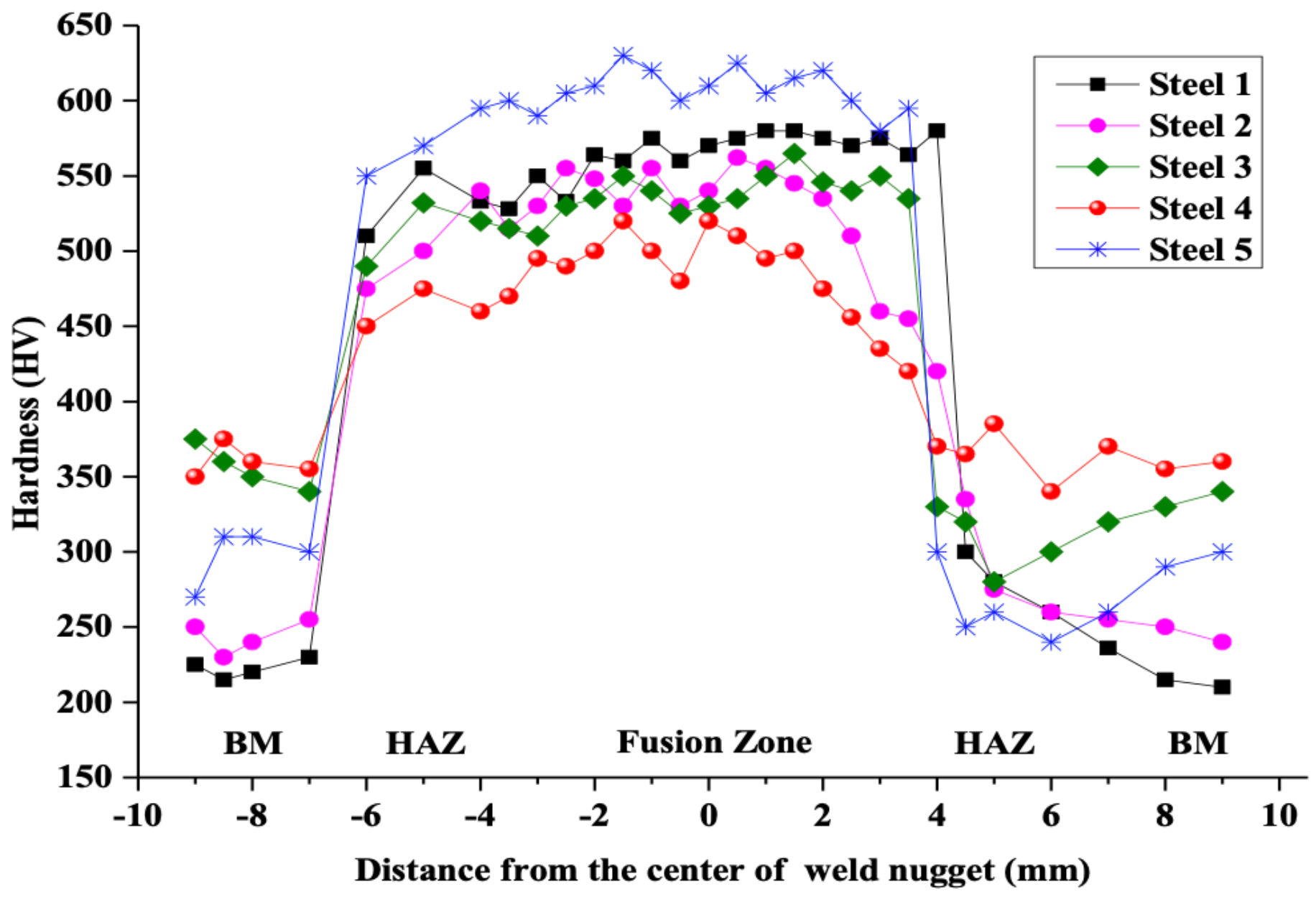

Figure 4

Hardness profiles of weld regions 


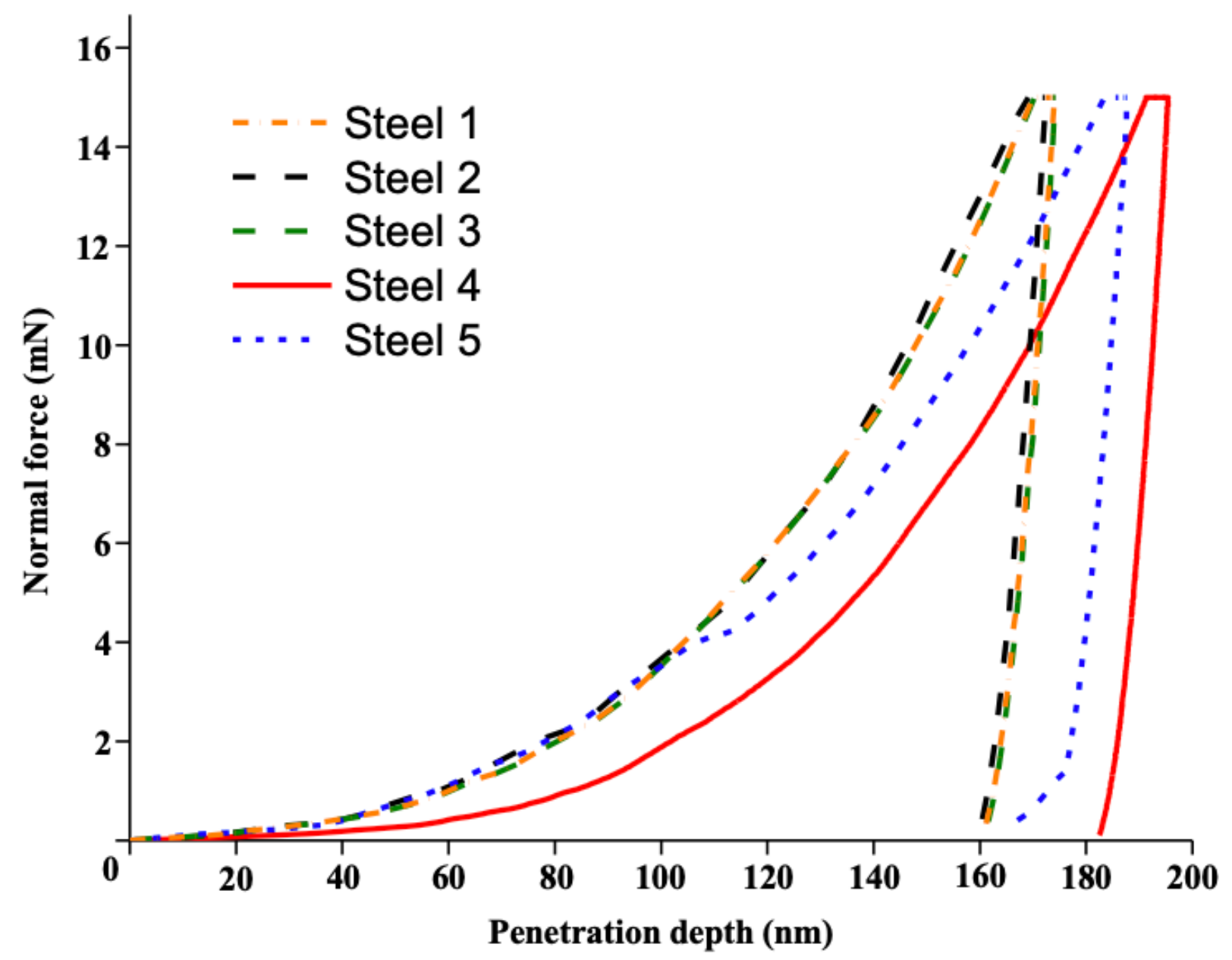

Figure 5

Penetration depth Vs Normal force 


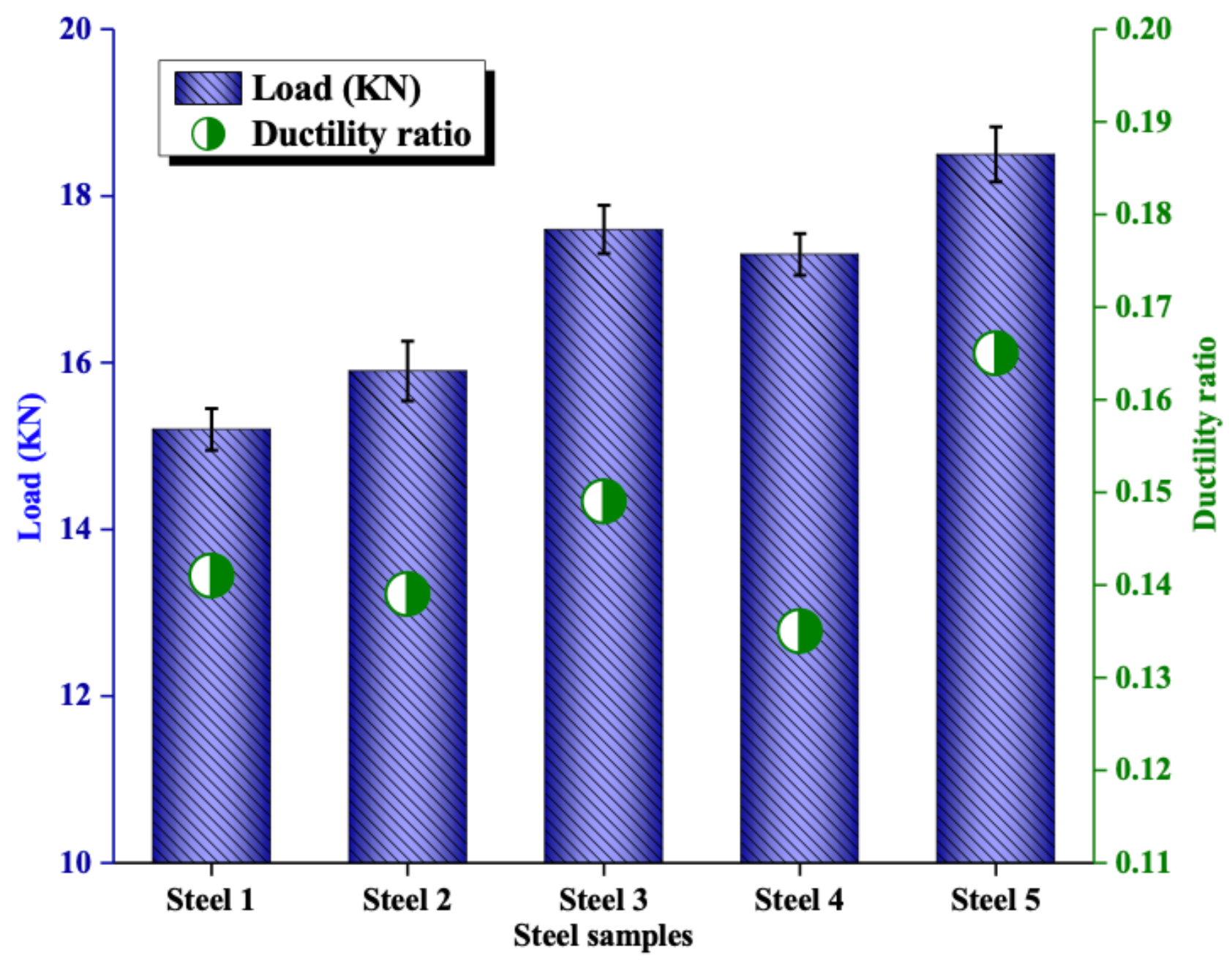

Figure 6

Maximum force and ductility ratio (CTS / TSS) 


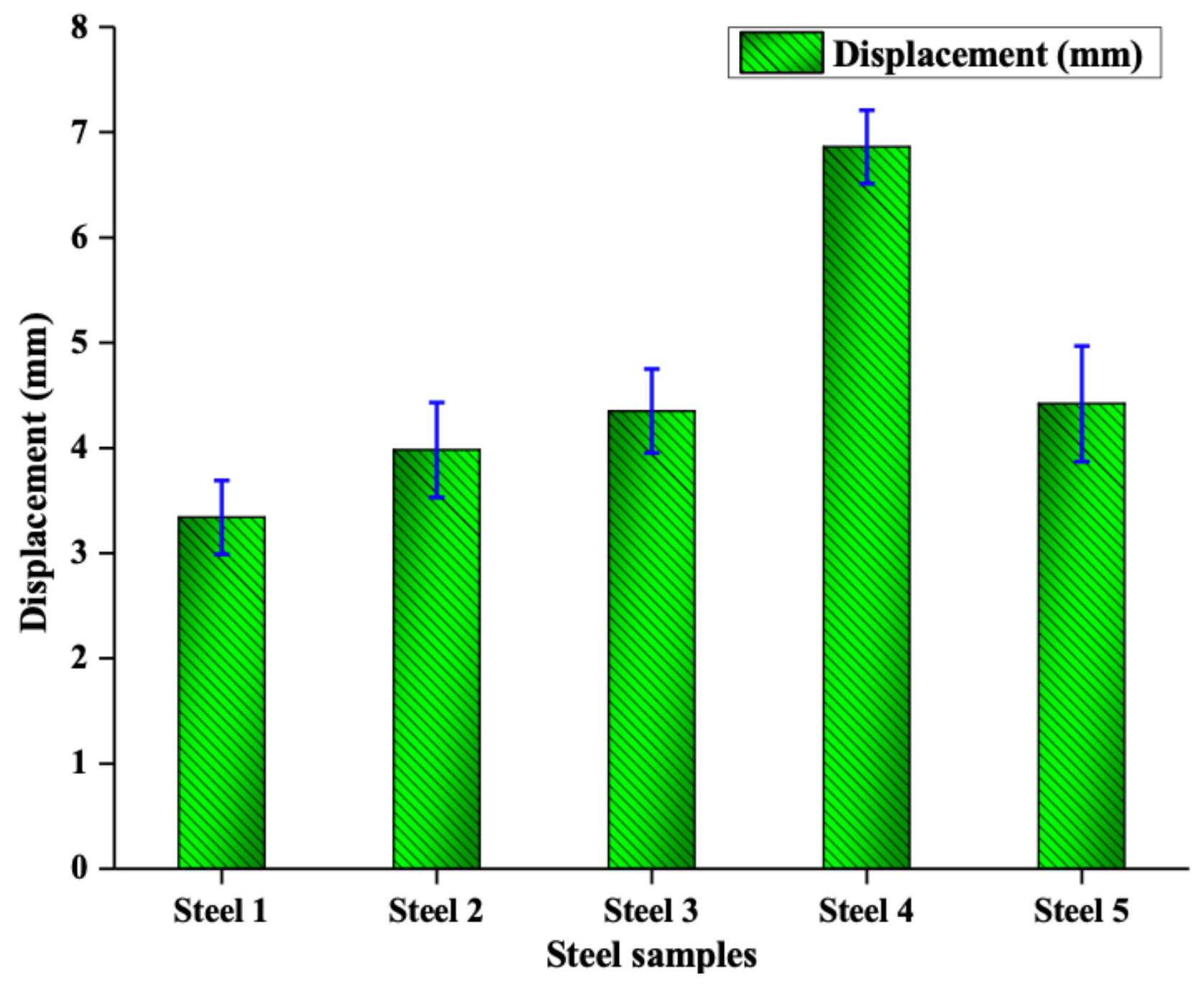

Figure 7

Displacement in cross-tension samples 


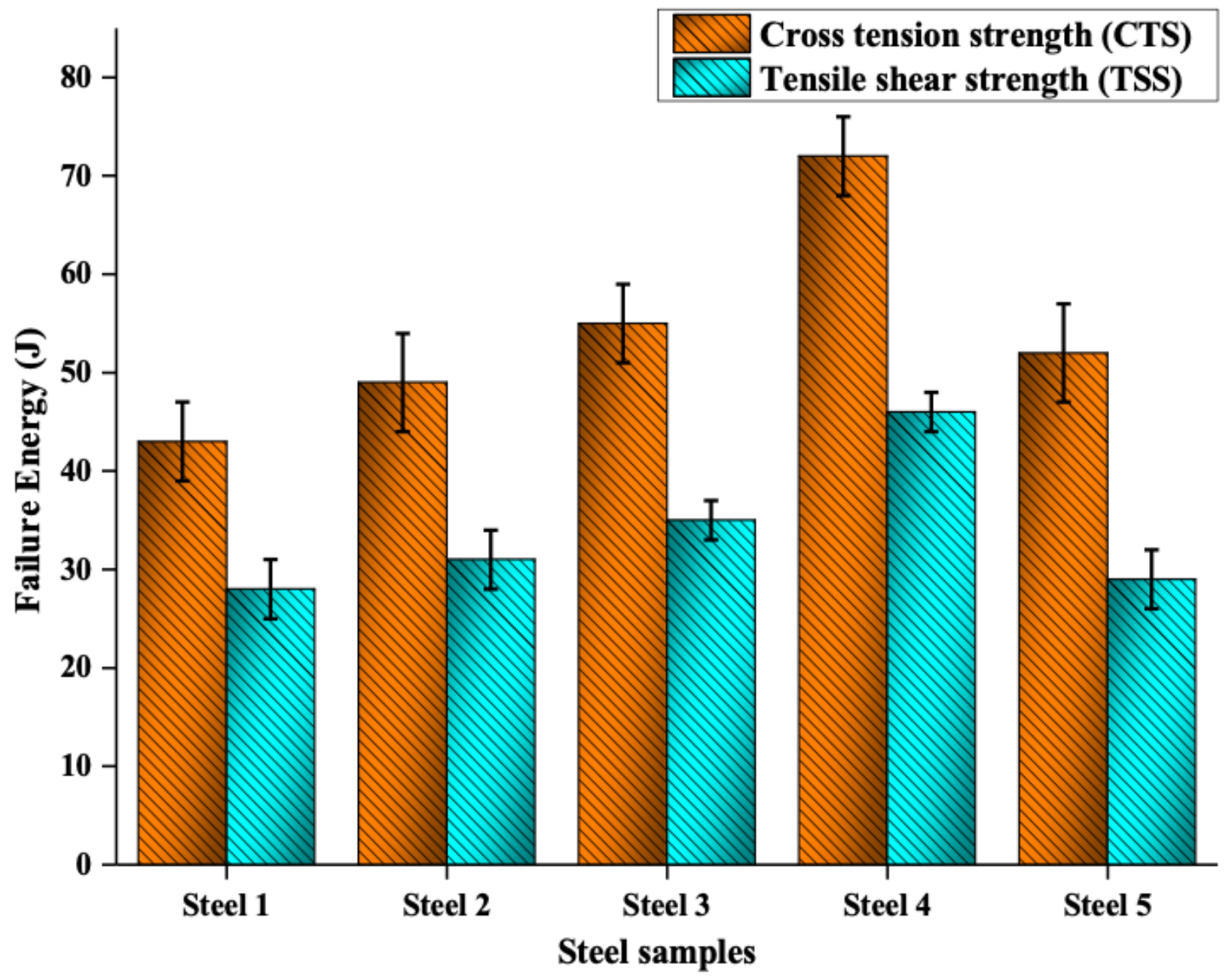

Figure 8

Failure energy study 


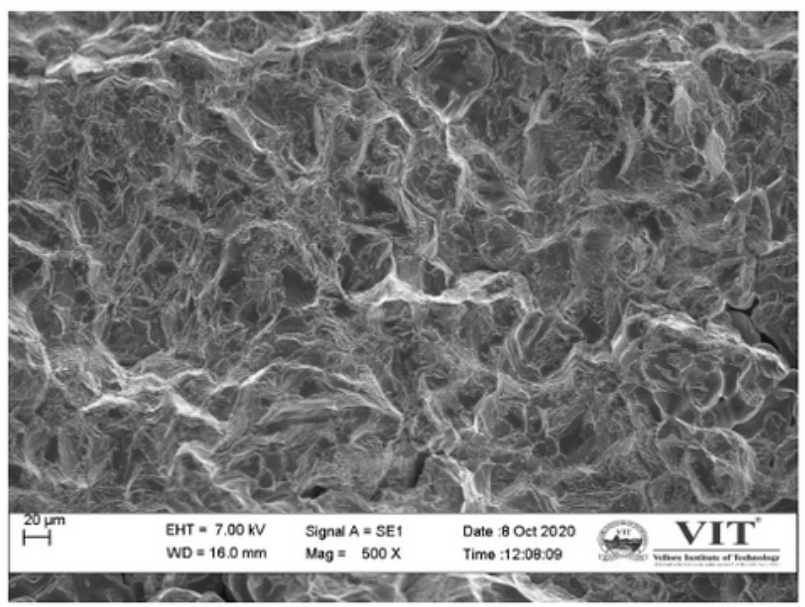

a) Steel 1

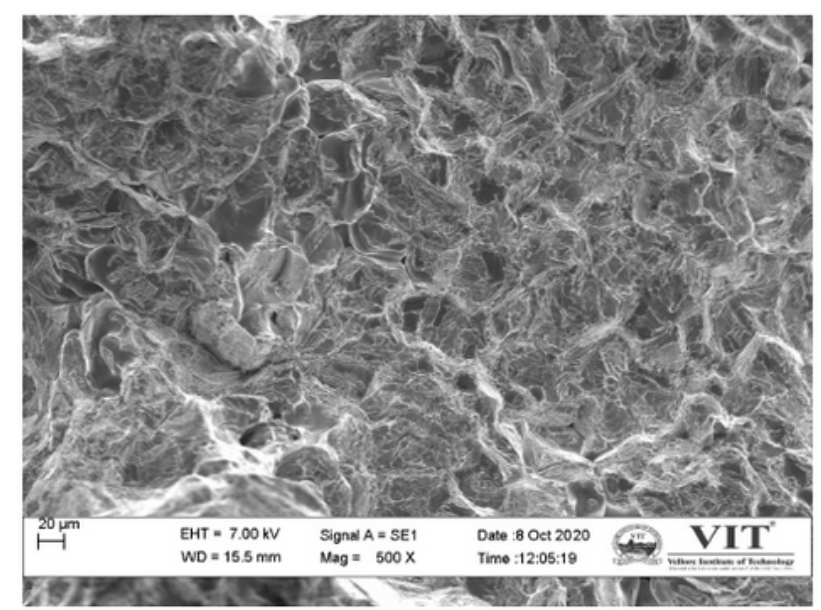

b) Steel 2

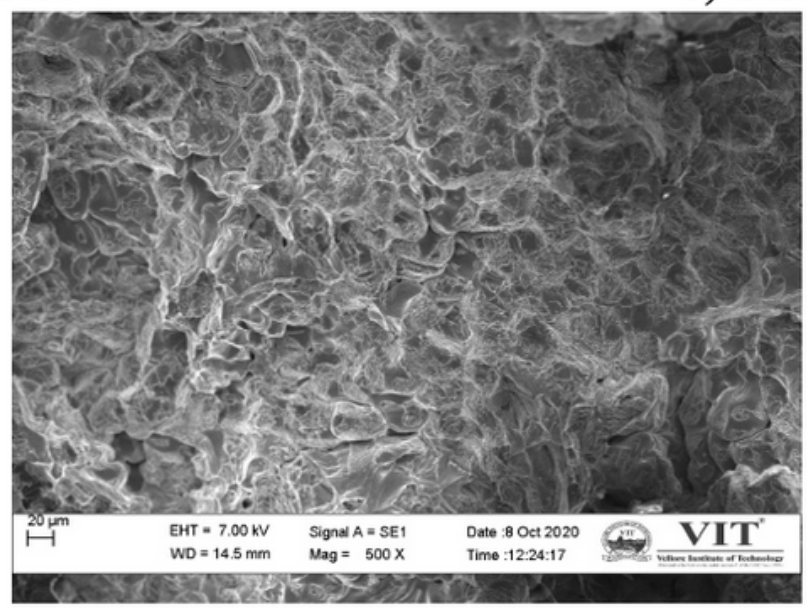

c) Steel 3

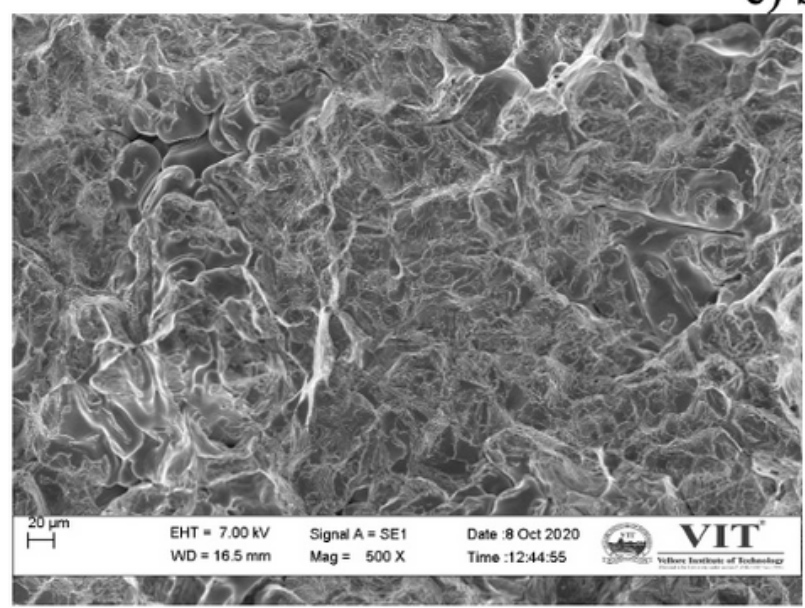

d) Steel 4

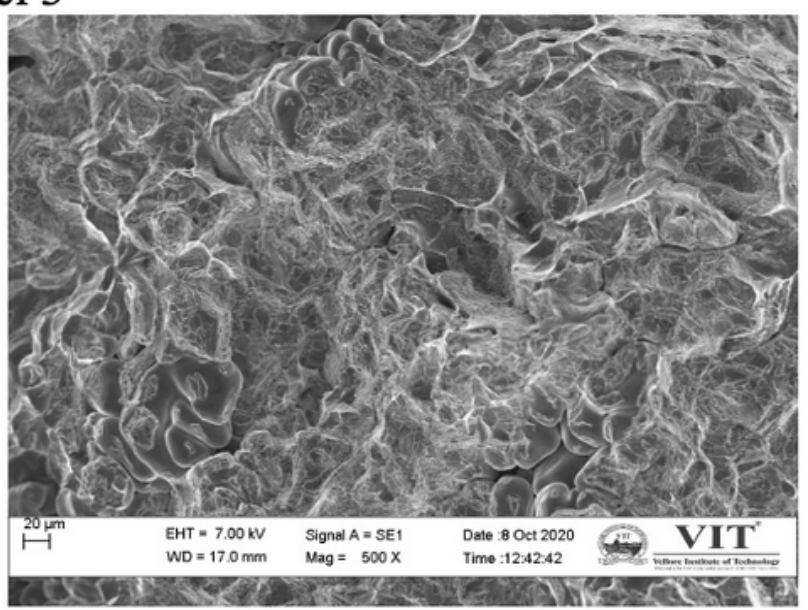

e) Steel 5

\section{Figure 9}

Fracture surface of weld steels 